\title{
Characteristics of Veterans diagnosed with seizures within Veterans Health Administration
}

\author{
Rizwana Rehman, PhD; ${ }^{\text {* }}$ Pamela R. Kelly, DHA, MBA/HCM; ${ }^{1}$ Aatif M. Husain, MD; ${ }^{1-2}$ Tung T. Tran, MD, MS ${ }^{1-2}$ \\ ${ }^{1}$ Southeast Epilepsy Centers of Excellence, Durham Department of Veterans Affairs Medical Center, Durham, NC; \\ ${ }^{2}$ Duke University Medical Center, Durham, NC
}

\begin{abstract}
The purpose of this report is to describe the demographics of Veterans diagnosed with seizures and taking antiepileptic drugs (AEDs) within the Veterans Health Administration (VHA) during fiscal year (FY) 2011 (October 1, 2010, to September 30, 2011), particularly with regard to comorbid traumatic brain injury (TBI) and posttraumatic stress disorder (PTSD). Information collected included age; sex; Operation Iraqi Freedom/Operation Enduring Freedom/Operation New Dawn (OIF/OEF/OND) status; and relevant encounter diagnosis codes for seizures, TBI, and PTSD. During FY11, 87,377 Veterans with seizures on AEDs were managed within the VHA. Prevalence was 15.5 per 1,000, and annual incidence was 148.2 per 100,000. The percentages of comorbid TBI and PTSD were $15.8 \%$ and $24.1 \%$, respectively. For OIF/OEF/ OND Veterans, these percentages increased to $52.6 \%$ and $70.4 \%$, respectively. PTSD and TBI are risk factors for both epilepsy and psychogenic nonepileptic seizures. Within the VHA, many Veterans experiencing seizures cannot be successfully treated with AEDs. The VHA Epilepsy Centers of Excellence promotes a multidisciplinary approach to increase and improve access to both epilepsy and mental health specialists for the care of epileptic and nonepileptic seizures.
\end{abstract}

Key words: epidemiology, epilepsy, incidence, Operation Enduring Freedom, Operation Iraqi Freedom, Operation New Dawn, posttraumatic stress disorder, prevalence, psychogenic nonepileptic seizures, seizures, traumatic brain injury, VHA health data.

\section{INTRODUCTION}

Epilepsy, a medical condition characterized by recurrent seizures, is the fourth most common neurological disorder in the United States. Veterans are at a higher risk of developing seizures than the general public, in part due to the increased rate of traumatic brain injuries (TBIs) experienced during combat and while in service [1-5]. In response to concerns of increased posttraumatic epilepsy among returning servicemembers from current conflicts, the U.S. Congress passed the Veterans' Mental Health and Other Care Improvements Act of 2008, mandating the establishment of the Veterans Health Administration (VHA) Epilepsy Centers of Excellence (ECoE). The ECoE

\footnotetext{
Abbreviations: $\mathrm{AED}=$ antiepileptic drug, $\mathrm{CBT}=$ cognitive behavioral therapy, ECoE = Epilepsy Centers of Excellence, EEG = electroencephalogram, FY = fiscal year, ICD-9-CM = International Classification of Diseases-9th Revision-Clinical Modification, IOM = Institute of Medicine, $\mathrm{OEF}=$ Operation Enduring Freedom, OIF = Operation Iraqi Freedom, OND = Operation New Dawn, PBM = Pharmacy Benefits Management, PNES = psychogenic nonepileptic seizures, PTSD = posttraumatic stress disorder, TBI = traumatic brain injury, VA = Department of Veterans Affairs, VHA = Veterans Health Administration, VSSC = VHA Support Service Center.

*Address all correspondence to Rizwana Rehman, PhD; Southeast Epilepsy Centers of Excellence, Durham VA Medical Center, Department of Medicine (111D), 508 Fulton St, Durham, NC 27705; 919-416-5982; fax: 919-4165919. Email: rizwana.rehman@va.gov
} http://dx.doi.org/10.1682/JRRD.2014.10.0241 
are expected to leverage technology, enhance affiliation, expand research opportunities, and improve access for specialized quality care for cost-intensive epilepsy services.

A recent Institute of Medicine (IOM) report, "Epilepsy across the spectrum: Promoting health and understanding," emphasized improving surveillance and early identification so that disease management programs can efficiently utilize resources, standardize practice patterns, and improve prevention and intervention outcomes [6]. This report also echoed recommendations by the International League Against Epilepsy that actions are needed to improve reporting on key attributes of epilepsy, including prevalence, incidence, and comorbidities in addition to other factors [7].

The VHA is the United States' largest integrated health system that serves a distinct patient population [8]. In order to maximize and centralize VHA ECoE resources, understanding the population of Veterans who will be referred for treatment of seizures is important. It is noteworthy that not all Veterans suspected of having seizures actually have epilepsy. For example, comorbid mild TBI, which is the majority of TBI, and posttraumatic stress disorder (PTSD) are associated with psychogenic nonepileptic seizures (PNES) [9-10]. Thus, patients' treatment should be appropriately individualized to address their needs. Understanding the frequency and demographics of Veterans treated for seizures could lead to better distribution of resources and to better care of Veterans. Currently, the VHA population mostly consists of Veterans of older wars. In the wake of the more recent Iraq and Afghanistan conflicts (Operation Iraqi Freedom [OIF]/Operation Enduring Freedom [OEF]/ Operation New Dawn [OND]) and multiple deployments of military personnel, monitoring of returning Veterans becomes imperative. A systemic review on complications of mild TBI estimated that 12 to 23 percent of servicemembers returning from OIF/OEF/OND experienced a TBI in deployment [11]. A congressional study found that among OIF/OEF patients treated by the VHA from 2004 through 2009, 21 percent were diagnosed with PTSD [12]. Among OIF/OEF/OND Veterans who used the VHA from October 01, 2001, to September 30, 2012, approximately 28.9 percent had a diagnosis of PTSD [13]. As the members of this subcohort of Veterans separate from Active Duty, their use of VHA resources is expected to increase. While prevalence and incidence estimates of epilepsy for fiscal year (FY)05-FY06 for geriatric and FY08-FY09 for OIF/OEF populations were published in the 2012 IOM report [6], to date, similar estimates are not available for general VHA patients.

This article is the result of an initiative of the ECoE to determine the demographic profile of patients diagnosed with seizures and treated with antiepileptic drugs (AEDs) in the VHA for monitoring purposes. Results are important for data-driven decisions for distribution of resources. In this article, we review data on the prevalence and incidence of seizure diagnoses among Veterans being treated with AEDs in the VHA during FY11 (October 01, 2010-September 30, 2011). Estimates of sex, age, and comorbid diseases, including TBI and PTSD, are provided. Analyses of OIF/OEF/OND Veterans with seizures as a subgroup are also presented. Recognizing major problems and challenges associated with diagnosing and treating seizures with AEDs may lead to substantial improvements in the access to quality care for our nation's Veterans.

\section{METHODS}

\section{Data Collection}

The VHA Support Service Center (VSSC) provided encounter data based on International Classification of Diseases-9th Revision-Clinical Modification (ICD-9$\mathrm{CM}$ ) seizure codes using inpatient and outpatient data files. These data were used in conjunction with national VHA Pharmacy Benefits Management (PBM) records to identify patients and their characteristics. Patients who received an AED for at least $30 \mathrm{~d}$ during FY11 were initially considered. AEDs included Carbamazepine, Ethosuximide, Felbamate, Gabapentin, Lacosamide, Lamotrigine, Levetiracetam, Oxcarbazepine, Phenobarbital, Phenytoin, Pregabalin, Primidone, Tiagabine, Topiramate, Valproate, Vigabatrin, and Zonisamide.

Encounter data of patients on AEDs were evaluated for seizure diagnosis (ICD-9-CM code of 345.xx [epilepsy] or 780.39 [convulsions]) within the past $3 \mathrm{yr}$ (FY09-FY11: October 01, 2008-September 30, 2011). Patients prescribed at least $30 \mathrm{~d}$ of an AED in FY11 with a seizure diagnosis during FY09-FY11 were considered seizure patients for prevalence purposes, as similarly used in the 2012 IOM report [6]. We used $3 \mathrm{yr}$ of diagnostic data to ensure the inclusion of both chronic seizure patients and incident cases.

FY10-FY11 PBM data and FY09-FY11 diagnoses data were used to identify new cases of seizures in the VHA. 
Among patients who were prescribed an AED in FY11 but not in FY10, those who had at least one seizure encounter in FY11 were considered as potential incident cases. Patients who did not have any seizure diagnosis 2 yr prior to FY11 were considered new incident seizure patients.

Demographic information of identified seizure patients was obtained from VSSC data files to determine sex, age, and OIF/OEF/OND status. Three age groups were used to describe and understand characteristics of young, middle-aged, and geriatric Veterans:

1. Young: Patients less than or equal to $45 \mathrm{yr}$ old.

2. Middle-aged: Patients 46 to 64 yr old.

3. Geriatric: Patients 65 yr or older.

ICD-9-CM codes were used for the identification of patients with TBI and PTSD among the seizure cohort. Using a look-back period of 5 yr (FY07-FY11), individuals with diagnoses of PTSD (ICD-9-CM 309.81) and TBI were identified. TBI-related diagnosis codes were adopted from the TBI case definition of the Armed Forces Health Surveillance Center, which is consistent with the Department of Defense standard surveillance case definition of TBI [14].

\section{Data Analysis}

Statistical analyses were performed using SAS version 9.2 (SAS Institute Inc; Cary, North Carolina). To evaluate differences in age group distributions, chisquare tests at 95 percent confidence level were conducted between prevalent seizure patients and incident seizure patients.

\section{RESULTS}

\section{Demographics}

During FY11, 5,637,750 Veterans received inpatient or outpatient care from the VHA. Figure 1(a) shows the demographics of 5,637,662 patients available and their overall and sex-specific age group distributions. Female Veterans comprised 8.8 percent of VHA patients. Figure 1(b) shows a similar distribution for the 87,377 Veterans diagnosed with seizures, i.e., prevalent cases. Female Veterans with seizures comprised 6.8 percent of seizure patients. Figure 1(c) displays incident (new onset of seizures in the VHA) age group distribution as well as sexspecific distributions. The percentage of females among incident cases of seizure patients was 6.6 percent, which was similar to the proportion of women among prevalent seizure patients.

Incidence of seizures in the VHA can be computed as a percentage of prevalence. In FY11, 9.6 percent $(8,357$ out of 87,377 ) of all VHA seizures cases were new incident cases. Furthermore, there was a statistically significant difference $\left(\chi^{2}=497, p<0.001\right)$ between age group distributions of new (incident) versus chronic seizure patients. Approximately 20.0 percent of all incident cases were in the young age group compared with only 12.6 percent among chronic patients in the same age group.

\section{Prevalence and Incidence}

Table 1 shows the annual FY11 crude and agespecific prevalence (per 1,000 VHA patients) and incidence (per 100,000 VHA patients) per year. Prevalence was 15.5 for all VHA patients, 15.9 for males, and 11.9 for females. Among all patients, prevalence was highest for middle-aged patients for both sexes: 20.1 for males and 14.2 for females.

The annual incidence per 100,000 was 148.2 for all VHA patients, 151.9 for males, and 110.2 for females. Highest rates were observed among the young age group for all patients and the male and female cohorts: 182.0, 197.7, and 128.6, respectively.

\section{OIF/OEF/OND Subcohort}

Overall, 476,520 OIF/OEF/OND Veterans received care in the VHA. Female Veterans comprised 12.6 percent of the OIF/OEF/OND VHA population. The age group profile of OIF/OEF/OND Veterans showed that 82.1 percent of OIF/OEF/OND patients fell in the young age category. On the other end of the age spectrum, only 0.3 percent of $\mathrm{OIF} / \mathrm{OEF} / \mathrm{OND}$ Veterans were geriatric patients.

Similar age group and sex distributions for the OIF/ OEF/OND prevalent seizure patients were observed. There were 3,792 (4.3\%) OIF/OEF/OND seizure patients among 87,377 Veterans diagnosed with seizures, i.e., prevalent cases. Female Veterans comprised 11.2 percent of the OIF/OEF/OND population with seizures. Approximately 86.3 percent of OIF/OEF/OND seizure patients fell in the young age group. Only six OIF/OEF/OND Veterans with seizures were identified as geriatric.

Among prevalent cases of seizures, approximately 4.3 percent were OIF/OEF/OND Veterans, whereas among incident cases of seizures, approximately 9.0 percent (749 out of 8,357 patients) belonged to the OIF/OEF/OND 


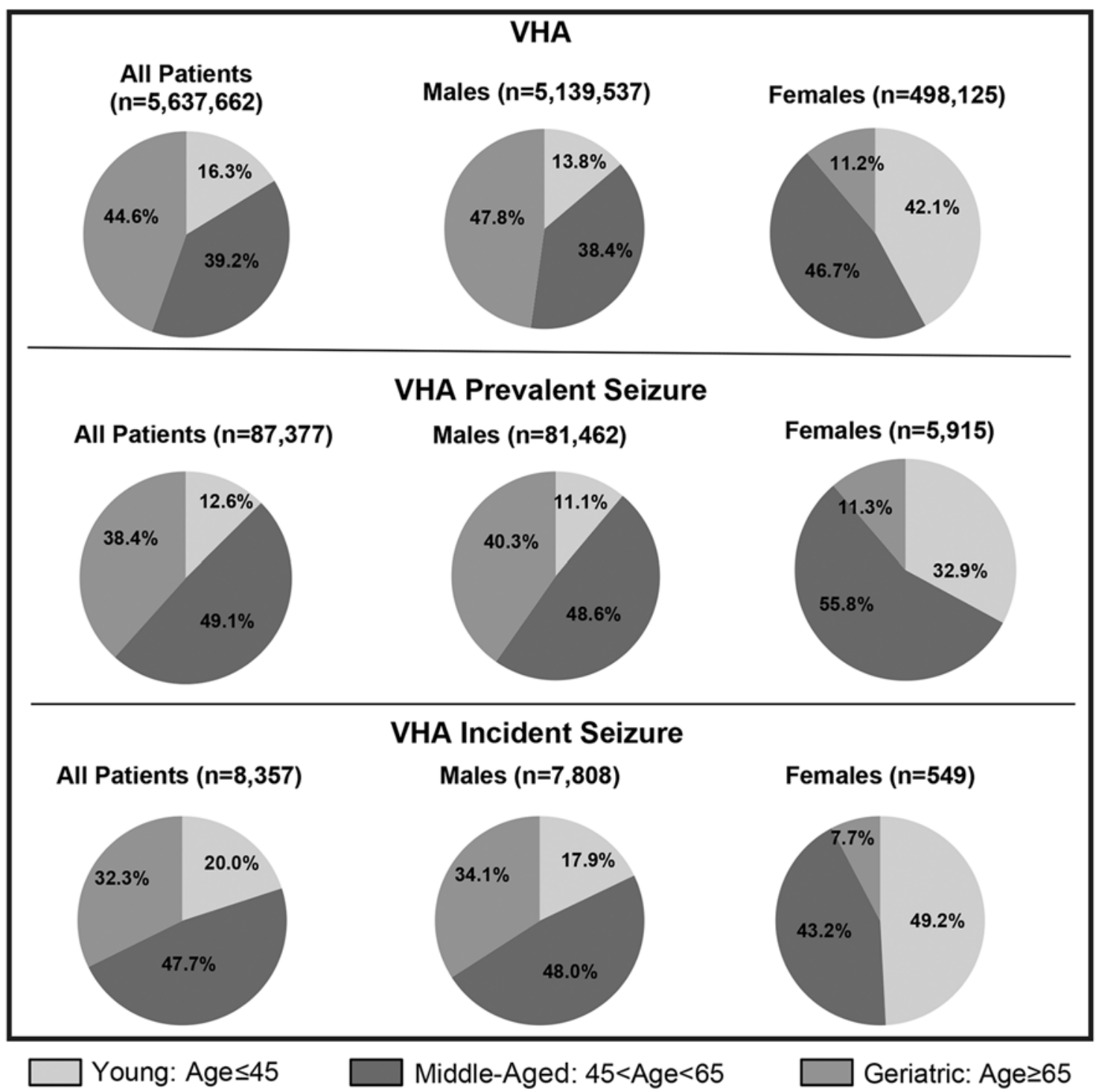

Figure 1.

Age group distributions for all Veterans Health Administration (VHA) and VHA seizure patients for fiscal year 2011. Note: Numbers rounded to nearest one decimal digit for percentages.

group. These incident cases were 19.8 percent (749 out of 3,792) of the OIF/OEF/OND cohort. Females comprised 14.4 percent of the OIF/OEF/OND new onset of seizure cohort. Approximately 90 percent of the incident OIF/ OEF/OND cohort was in the young age group category.

Table 2 shows the prevalence and incidence estimates of seizures among OIF/OEF/OND Veterans. Among OIF/OEF/OND Veterans, the incidence rates were 157.2 for all patients, 160.9 for males, and 131.2 for females. In particular for the young age group, the rates were 176.2 for males and 146.6 for females.

\section{Comorbid Diseases, Traumatic Brain Injury, and Posttraumatic Stress Disorder}

Figure 2 shows the percentage of TBI and PTSD among seizure prevalent and incident cohorts for all patients and sex-specific groups. Among all VHA Veterans with prevalent seizures, the percentage of TBI was 
Table 1.

Veterans Health Administration seizure diagnosis frequency measures for fiscal year 2011 (point estimate, 95\% confidence interval).

\begin{tabular}{lcc}
\hline \multicolumn{1}{c}{ Cohort } & Prevalence Per 1,000 Patients & Incidence Per 100,000 Patients \\
\hline All Patients & $15.5(15.4-15.6)$ & $148.2(145.1-151.4)$ \\
Young & $12.0(11.9-12.1)$ & $182.0(173.2-190.7)$ \\
Middle-Aged & $19.4(19.2-19.6)$ & $180.5(174.9-186.1)$ \\
Geriatric & $13.3(13.2-13.4)$ & $107.5(103.5-111.6)$ \\
Males & $15.9(15.8-16.0)$ & $151.9(148.6-155.3)$ \\
Young & $12.8(12.5-13.1)$ & $197.7(187.7-208.1)$ \\
Middle-Aged & $20.1(19.9-20.3)$ & $189.8(183.8-195.9)$ \\
Geriatric & $13.4(13.3-13.5)$ & $108.2(104.1-112.4)$ \\
Females & $11.9(11.6-12.2)$ & $110.2(100.1-119.4)$ \\
Young & $9.3(8.9-09.7)$ & $128.6(113.3-144.0)$ \\
Middle-Aged & $14.2(13.7-14.7)$ & $101.9(88.9-114.9)$ \\
Geriatric & $12.0(11.1-12.9)$ & $75.4(52.6-98.3)$ \\
\hline Note: Young: $\leq 45$ yr, Middle-Aged: 46-64 yr, and Geriatric: $\geq 65$ yr. & \\
\hline
\end{tabular}

Table 2.

Veterans Health Administration Operation Iraqi Freedom/Operation Enduring Freedom/Operation New Dawn seizure diagnosis frequency measures for fiscal year 2011 (point estimate, 95\% confidence interval).

\begin{tabular}{lcc}
\hline \multicolumn{1}{c}{ Cohort } & Prevalence Per 1,000 Patients & Incidence Per 100,000 Patients \\
\hline All Patients & $8.0(7.7-8.3)$ & $157.2(145.9-168.4)$ \\
Young & $8.4(8.1-8.7)$ & $172.3(159.3-185.3)$ \\
Middle-Aged & $6.1(5.6-6.6)$ & $89.2(69.0-109.4)$ \\
Males & $8.1(7.8-8.4)$ & $160.9(148.8-173.1)$ \\
Young & $8.5(8.2-8.8)$ & $176.2(162.1-190.2)$ \\
Middle-Aged & $6.3(5.7-6.9)$ & $94.6(72.6-116.5)$ \\
Females & $7.0(6.3-7.7)$ & $131.2(102.2-160.1)$ \\
Young & $7.4(6.7-8.1)$ & $146.6(113.5-179.8)$ \\
Middle-Aged & $4.7(3.3-6.1)$ & $44.4^{*}$ \\
\hline
\end{tabular}

Note: Young: $\leq 45$ yr and Middle-Aged: 46-64 yr.

*Estimates based on counts $<20$ are unstable.

15.8 percent (Figure 2(a)). For PTSD, the percentages were 24.1 percent among all seizure patients. For Veterans with seizures and both TBI and PTSD, the percentages were 6.5 percent for all, 6.4 percent for males, and 7.8 percent for females. Not shown in Figure 2, among patients with TBI, 24.0 percent are young, 57.2 percent are middle-aged, and 18.8 percent are geriatric. For PTSD, the percentages are 21.7, 63.4, and 14.9 percent, respectively. For comparison with all VHA patients in FY11, a separate query showed that the overall percentages of patients with TBI and PTSD were 3.4 and 16.0 percent, respectively.

Figure 2(b) shows the percentages of TBI, PTSD, and both TBI and PTSD among all incident cases of Veterans with seizures. Figure 3 shows the percentages of
TBI, PTSD, and both comorbid diseases in the OIF/OEF/ OND seizure cohort. For PTSD, the percentages were 61.6 (all), 62.7 (males), and 51.9 percent (females).

\section{DISCUSSION}

The algorithm used in this study was developed to identify patients with epilepsy in managed healthcare organizations utilizing computerized administrative data systems, combining diagnosis and pharmacy data [15]. It is appropriate for the VHA because of the availability of extensive administrative databases and electronic health records within the VHA. Pugh et al. adopted this algorithm for findings published in the 2012 IOM report [6], and it has 


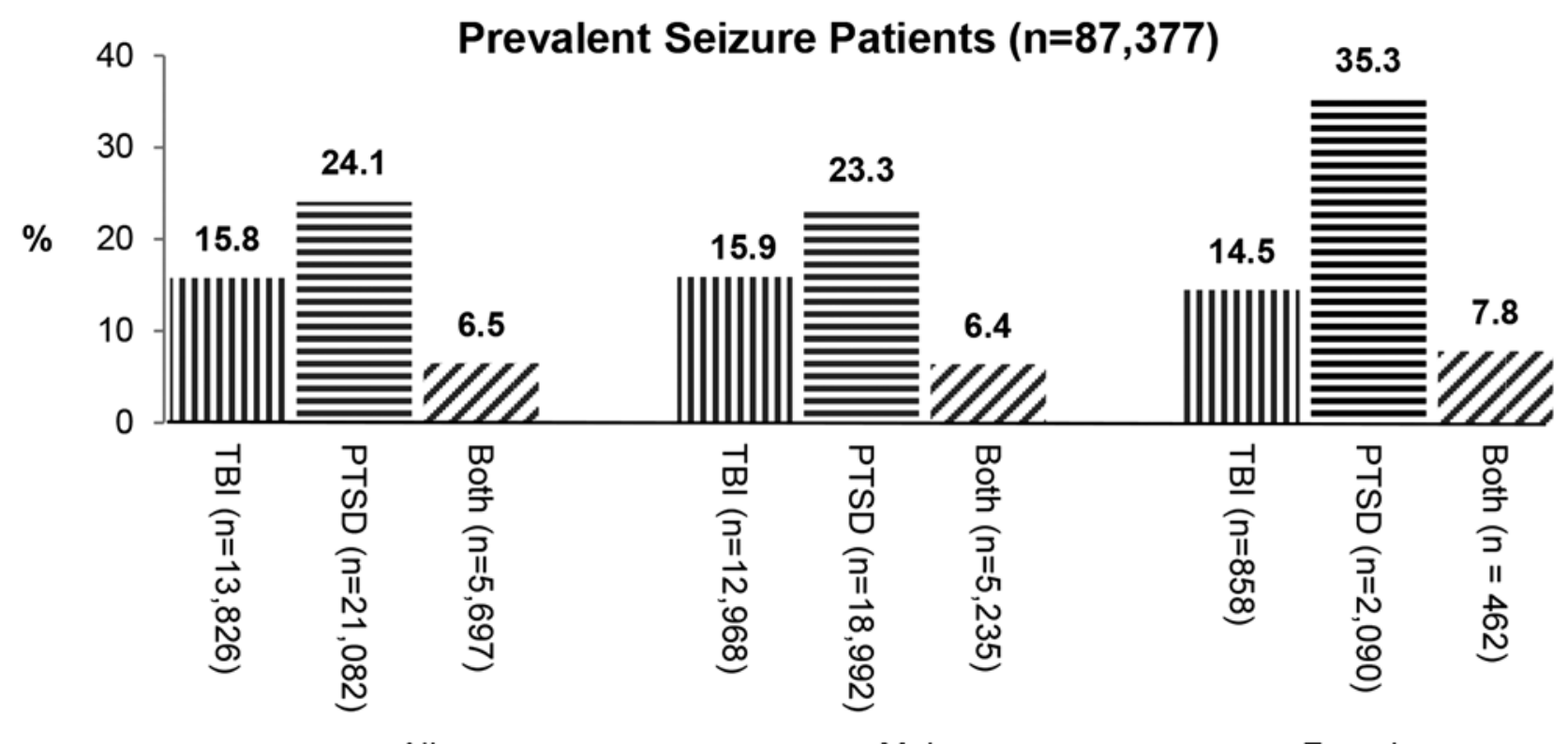

All

Males

Females

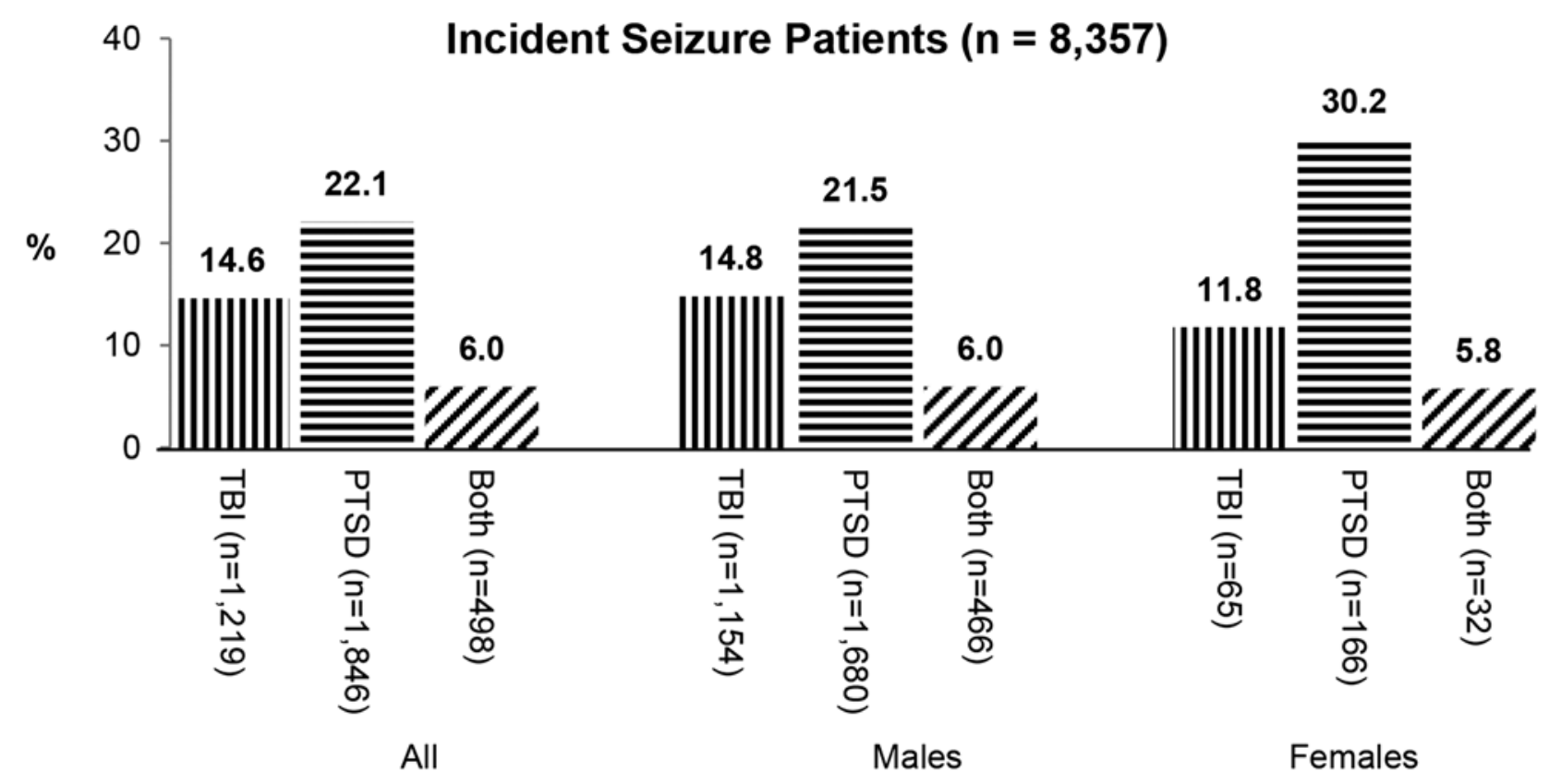

Figure 2.

Percentage of comorbid diseases among Veterans Health Administration seizure patients for fiscal year 2011. Note: Numbers rounded to nearest one decimal digit for percentages. PTSD = posttraumatic stress disorder, TBI = traumatic brain injury.

been used over the years for identifying older VHA patients with epilepsy for various research purposes [16-19]. This algorithm was validated for the VHA geriatric population, with a positive predictive value between 0.94 and 0.98
[17]. However, validation for the general VHA population has not been done and is currently underway.

While this algorithm has been in use to identify Veterans with epilepsy, it more precisely identifies patients who 


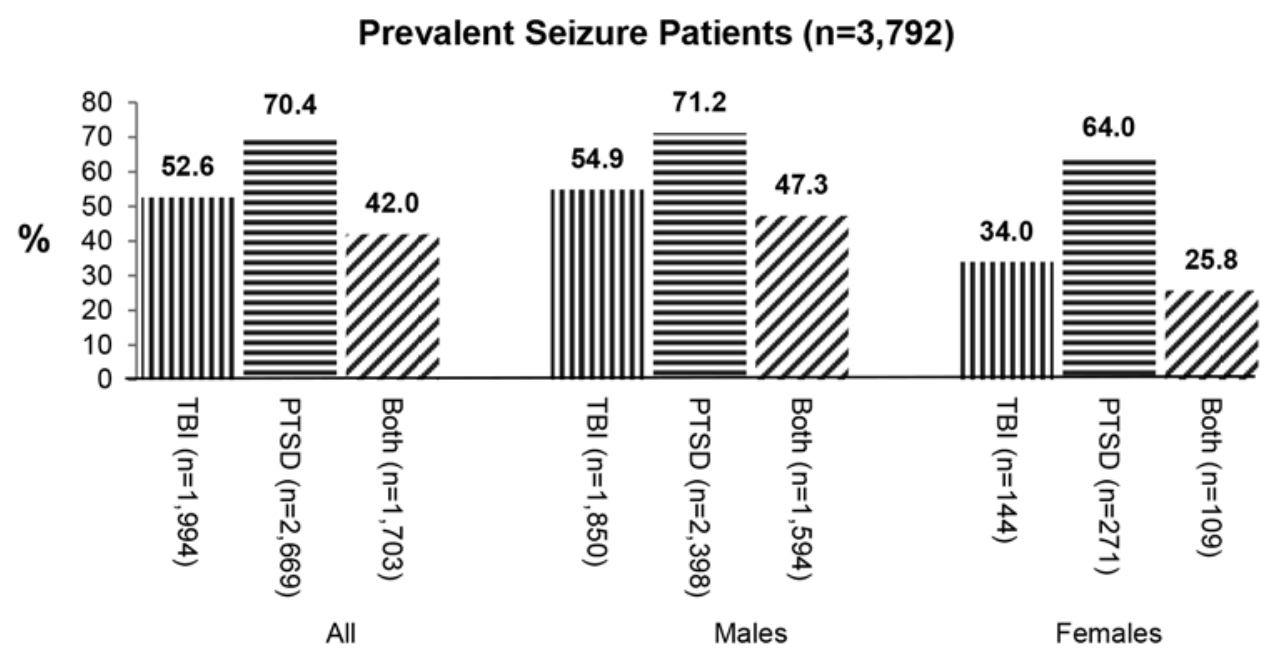

Incident Seizure Patients ( $n=749)$

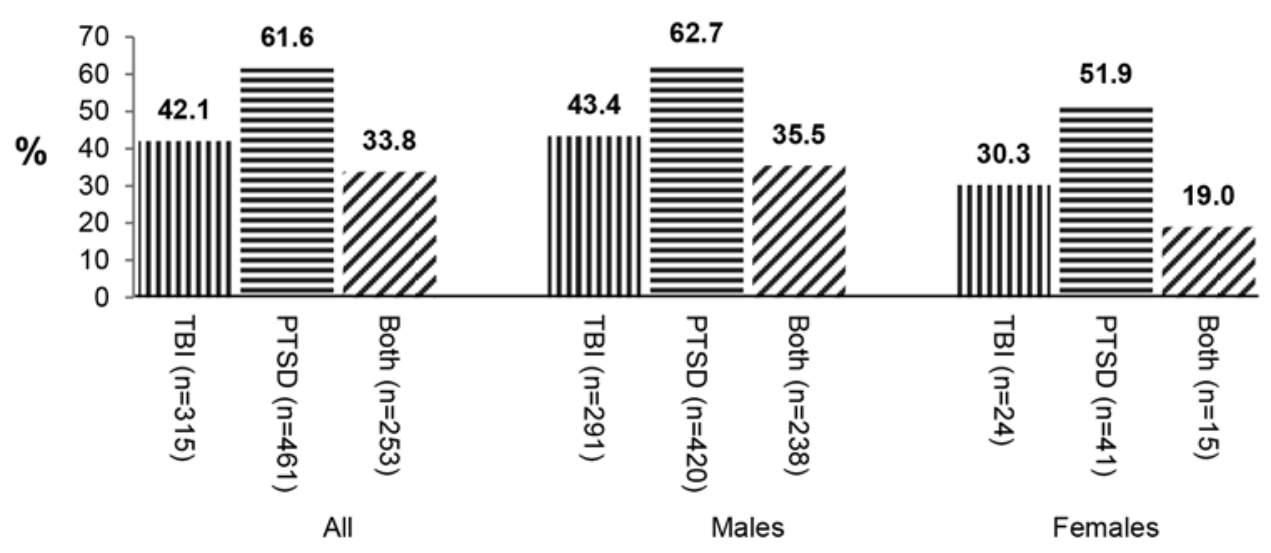

Figure 3.

Percentage of comorbid diseases among Veterans Health Administration Operation Iraqi Freedom/Operation Enduring Freedom/ Operation New Dawn seizure patients for fiscal year 2011. Note: Numbers rounded to nearest one decimal digit for percentages. PTSD = posttraumatic stress disorder, TBI = traumatic brain injury.

had an event concerning enough for an epileptic seizure that a provider coded a seizure diagnosis and prescribed an AED. According to the standards for epidemiologic studies presented in the International League Against Epilepsy Commission Report, this methodology captures probable cases of epilepsy [20]. In actuality, the diagnosis of epilepsy is often not straightforward. Sometimes physicians treat probable epileptic seizures with AEDs without confirming the diagnosis. Clinical history and outpatient tests are occasionally insufficient, and long-term admission to a specialized video epilepsy monitoring unit may be required to distinguish epilepsy from PNES and other causes for syncope and altered behaviors. Furthermore, many cases are not straightforward. For example, frontal lobe epilepsy may have unusual clinical presentations and limited electroencephalogram (EEG) findings. It is sometimes helpful to have multiple experienced epileptologists discuss difficult cases. Also, some patients have both epileptic and nonepileptic events. Therefore, we believe that the Veterans with seizure diagnoses on an AED identified in this study include not only those with epilepsy but also other medical conditions like PNES. Though patients with PNES may be a significant portion of those within the Department of Veterans Affairs (VA) treated for epilepsy, 
pulling them out directly is difficult, especially in an epidemiological study based on administrative data. Diagnosing PNES can be difficult even in an individual's case. It often involves extensive testing (e.g., video EEG monitoring), which many Veterans do not get. Furthermore, many patients have both PNES and epilepsy because one does not exclude the other. Methods trying to address ways to separate patients with PNES from those with epilepsy are underway. Hamid et al. used a natural language processing tool to identify PNES in Veterans who had video EEG and could only identify 22 out of 742 (3\%) with definite PNES only [21]. The vast majority (698 out of 742) did not get a definite diagnosis in their study [21]. Thus, directly identifying patients with PNES is difficult and possibly not much more accurate than inference. In addition to patients with epilepsy and PNES in our study, an unmeasured proportion may consist of patients who were prescribed AEDs for conditions other than epilepsy. Regardless, included patients had a seizure diagnosis and were prescribed an AED.

With this in mind, the estimates of seizure diagnoses from this study (prevalence: 15.5 per 1,000, incidence: 148.2 per 100,000 ) are notably high. Comparison of epidemiological studies among different groups and populations is complicated due to different structures of populations, definitions of epilepsy, and study designs [22]. VHA data may not be suitably compared with the general population for two reasons. First, Veterans are at a higher risk of developing seizure due to the nature of their military jobs. Second, the denominators for computing the prevalence and incidence in the VHA are composed of a sick population, whereas the general population estimates are based on healthy and sick.

Our provided statistics may not be comparable with the rates reported for managed care organizations and clinical populations due to biases that can occur because of different age groups and sex distributions. A summary of crude estimates from previous studies is presented next. Prevalence estimates per 1,000 of epilepsy for clinical populations included in the 2012 IOM report ranged between 4.0 and 10.2 [6]. The Centers for Disease Control and Prevention's Behavioral Risk Factor Surveillance System estimated an active epilepsy prevalence of 8.4 in 2005 [23]. The South Carolina Epilepsy Surveillance System reported annual incidence of 99 [6]. Among managed care organizations, an annual incidence of 77 was estimated for patients who were continuously enrolled for 5 yr [24].
According to the VHA Office of Public Health's most recent epidemiology report, about 60 percent of all separated OIF/OEF/OND Veterans have used the VA healthcare system since October 1, 2001 [25]. As more and more OIF/OEF/OND Veterans seek care at the VA, the need for focused specialized care of young and female seizure patients will grow. Data from our study showed that OIF/OEF/OND Veterans are younger and consist of more females than Veterans of previous wars. Similar trends were observed for OIF/OEF/OND Veterans experiencing seizures. In addition, Table 2 shows that among both males and females, the highest incidence rates were found for young patients (176.2 for males, 146.6 for females).

Our prevalence study results are consistent with those published in the 2012 IOM report of the FY08-FY09 OIF/ OEF VHA patient population [6]. However, estimated incidence rates in our FY11 study are higher. It is important to note that inclusion criterion in the epilepsy cohort referenced in the 2012 IOM report was based on deployment to a war zone. The reported prevalence of epilepsy patients was 8.1 per 1,000 individuals and the incidence was 133 per 100,000 person-years. The prevalence of epilepsy for males was 8 per 1,000 and for females was 6 per 1,000 . The incidence was 140 per 100,000 person for males and 86 per 100,000 year for females [6]. A most recent published study based on FY10 data for OIF/OEF/ OND Veterans seeking care at the VHA found an epilepsy prevalence of 10.6 per 1,000 [26].

It is unclear whether the higher proportion of seizure diagnoses in the VHA is due to higher proportions of epileptic seizures, nonepileptic seizures, or both, because the actual percentage of nonepileptic seizures in most studies, as in this one, is not well known. It has been hypothesized that seizures in the Veteran population are linked to Veterans' history of combat exposure and resulting increased frequencies of TBI and PTSD. These comorbidities were measured in this study.

TBI was diagnosed among 3.4 percent and PTSD was diagnosed for 16.0 percent of all VHA Veterans in this study. However, among Veterans with epilepsy, these percentages increased to 15.8 percent for TBI and 24.1 percent for PTSD. Moreover, among OIF/OEF/ OND Veterans with epilepsy, these numbers increased further to 52.6 and 70.4 percent for TBI and PTSD, respectively. As noted previously in another study, an estimated 12 to 23 percent of servicemembers returning from OIF/OEF/OND experienced a TBI in deployment 
[11] and among OEF/OIF/OND Veterans who used the VHA from October 01, 2001, to September 30, 2012, approximately 28.9 percent had a diagnosis of PTSD [13]. It is not known what proportion of seizure diagnoses affected by TBI and PTSD in the Veteran population is epileptic versus nonepileptic; prior studies suggest more of the latter. PNES have been associated with comorbid mild TBI, which is the majority of TBI [9]. Severe TBI is better associated with epilepsy but represents a minority of TBI cases [27]. Also, Veterans with PTSD are at higher risk of having PNES [10]. Therefore, higher proportions of TBI and PTSD in Veterans, particularly OIF/OEF/OND Veterans, suggest that a considerable number of patients diagnosed with epilepsy actually have PNES.

This is clinically relevant because it influences the care of Veterans diagnosed with seizures by primary care and specialists equally. Misdiagnosis of PNES as epilepsy due to incomplete evaluations can lead to years of ineffective and potentially harmful use of AEDs without addressing the underlying cause of disability. AEDs, like any prescription medication, can cause adverse effects. As a class, they are known to cause cognitive impairments and mood disturbances. In 2009, the Food and Drug Administration mandated that patients taking AEDs be warned about increased risk of suicidal thoughts. It is worth noting that Veterans with TBI and PTSD are more likely to die by suicide [28-29]. Other serious side effects associated with some AEDs include liver dysfunction, blood disorders, and life-threatening rashes. Medicationadverse effects are often compounded in elderly patients requiring multiple drugs. Chronic use of AEDs can have a negative effect on bone health because of the increased risk of osteoporosis. Also, many AEDs interact with other medications because of shared pathways of metabolism or excretion.

All of this emphasizes the need to identify the correct diagnosis before subjecting Veterans to unnecessary treatment risk. When patients with PNES are misdiagnosed as epileptic, the missed opportunity to treat the actual illness can have a profound negative effect. Untreated PNES can be as devastating as epilepsy because both disrupt Veterans' lives. They may not be able to drive or work and may often experience the same stigma and anxiety associated with epilepsy. Like with PTSD, Veterans with PNES also need increased mental health resources. Identifying and treating the underlying causes of PNES is often difficult. Even in the general population, there are not enough providers who specialize in the treatment of PNES, partially because of the relatively low compensation per amount of effort required. Treating PNES is time-consuming and often requires extensive training and experience. The patient population is diverse and success is inconsistent. While cognitive behavioral therapy (CBT) may be the most popular treatment technique, how to use CBT or other treatments is debated. The best solution may involve an integrative approach.

Particularly within the VHA, where there should be a more cooperative approach to treat a high-risk population, there needs to be collaboration among disciplines. Epilepsy specialists should help guide care of the paroxysmal events as well as involve primary care and mental health services for treatment of PNES, TBI, and/or PTSD. The addition of clinical psychologists for newly developed specialized CBT of patients with PNES is currently being considered as a part of the ECoE improvement and expansion of service plans [30-31].

Efficient care of Veterans is becoming even more important because the demographics from FY11 show that more young Veterans are being diagnosed with seizures. Incidence estimates of seizures in this study are highest for Veterans in the young age group. Also, there is a statistically significant shift in the age distribution of prevalent versus incident cases from an older population to a younger one. This increase in seizure diagnoses in younger Veterans may be related to the higher proportion of PTSD and TBI in the younger population, as mentioned in the "Results" section, which may correlate to increased proportions of PNES. The implementation of telehealth options, including clinical video telehealth and tele-EEG, are key efforts to address efficiency and outreach.

\section{LIMITATIONS}

There are several limitations to this study. First, the VHA population has multiple characteristics different from the general population with respect to both age and health status. For example, not all Veterans seek care within the VHA, suggesting a selection bias to those who need medical care. Second, while prevalence was measured for $1 \mathrm{yr}$, a nonstandard $3 \mathrm{yr}$ of diagnosis data were used to ensure the inclusion of patients with chronic epilepsy along with incident cases. This is based on observations that clinic appointments are sometimes more than $2 \mathrm{yr}$ apart and coding for seizures are not done at every visit. A validation of these observations is in progress. Third, prevalent epilepsy without AEDs may have been 
excluded because the used algorithm required treatment with AEDs. While it is known that the severity of TBI may help distinguish seizure etiology [26], this information was not available in this study and thus may be useful in other future studies. As mentioned previously, the used algorithm combines seizure diagnosis and PBM data. Symptomatic seizures were accounted for by including patients for whom AEDs were prescribed for at least $30 \mathrm{~d}$. However, the algorithm could not tease out patients with symptomatic seizure if providers treated those with AEDs. The reported incidence should be interpreted as incidence of seizure in the VHA, not the incidence of disease. Some patients treated for other conditions such as pain and mental health disorder may have been included in the study. Finally, as discussed previously, it was not possible to distinguish between epileptic versus nonepileptic seizures.

\section{CONCLUSIONS}

In order to meet the specialized needs of the Veteran population experiencing seizures, the VHA adopted aggressive measures such as creation of the ECoE. This ECoE study shows that there is a relatively high prevalence and incidence of being diagnosed with seizures and being treated with AEDs for Veterans within the VHA. TBI and PTSD are both risk factors for epilepsy and PNES, and therefore, increased comorbid disease statistics allude to the challenging problem of correct diagnosis of seizures in the VHA. With the passage of time, further studies will be helpful in evaluating trends of epilepsy among the OIF/OEF/OND cohort.

ECoE is promoting a multidisciplinary approach that includes primary care, neurology, social work, and mental health. The integration of mental health services such as newly developed specialized CBT clinics for PNES and the implementation of telehealth through leveraging technology have already been deployed. Additional emphasis on the integration of primary care that treats the majority of less complicated seizure patients through educational resources and lean processes for maximization of resources will improve the VHA's ability to meet access and quality care demand. With the success of integration model, other managed care organizations can follow suit.

\section{ACKNOWLEDGMENTS}

\section{Author Contributions:}

Study design and concept: R. Rehman, P. R. Kelly, A. M. Husain. Data collection and analysis: R. Rehman.

Drafting of manuscript: R. Rehman, T. T. Tran, P. R. Kelly. Critical revision of manuscript for important intellectual content: R. Rehman, P. R. Kelly, A. M. Husain, T. T. Tran.

Financial Disclosures: Dr. Tran has received support from a financial relationship with UCB Pharma through a speaker honorarium. Dr. Husain has received support from financial relationships with UCB Pharma through research, consultation, and speaker bureau involvement; with Upsher Smith Laboratories through research and consultation; with Jazz Pharma through consultation and speaker bureau involvement; and with Demos Medical Publishing through royalties. The remaining authors have declared that no competing interests exist. This study was supported by the VHA for quality improvement and management of the ECoE. All authors are employees of VHA ECoE and required permission from the VHA Neurology Program Office to submit the manuscript for publication.

Funding/Support: This material was based on work supported by the VHA Neurology Program Office.

Additional Contributions: The authors would like to thank Cheryl Strickland, BS (VSSC Management and Program Analyst); Kenneth Bukowski, BS (PBM and Program Analyst); and Michele Eskridge (Program Specialist for MedSAFE) for providing data for this ECoE project. The authors are also indebted to Fran Cunningham, PharmD (Chief, VHA Center for Medication Safety), and Mary Jo Pugh, PhD (Research Health Scientist), for their helpful discussions, and Robert Ruff, MD, PhD (VHA Ex-Chief of Neurology), for his support. The authors would like to thank the anonymous reviewers whose suggestions improved the exposition of this article. No compensation was given to any contributor of this project.

Institutional Review: This study and the use of the data were reviewed and approved by the National VHA Neurology Program Office for publication purposes.

Participant Follow-up: The authors have no plans to notify the study subjects of the publication of this article because of a lack of contact information.

Disclaimer: The opinions expressed are solely those of the authors and do not necessarily represent the position of the VHA.

\section{REFERENCES}

1. Walker AE, Jablon S. A follow-up study of head wounds in World War II. Washington (DC): Veterans Administration; 1961.

2. Salazar AM, Jabbari B, Vance SC, Grafman J, Amin D, Dillon JD. Epilepsy after penetrating head injury. I. Clinical correlates: A report of the Vietnam Head Injury Study. Neurology. 1985;35(10):1406-14. [PMID:3929158] http://dx.doi.org/10.1212/WNL.35.10.1406

3. Hoge CW, McGurk D, Thomas JL, Cox AL, Engel CC, Castro CA. Mild traumatic brain injury in U.S. Soldiers 
returning from Iraq. N Engl J Med. 2008;358(5):453-63.

[PMID:18234750]

http://dx.doi.org/10.1056/NEJMoa072972

4. U.S. Institute of Medicine Committee on Gulf War and Health: Brain Injury in Veterans and Long-Term Health Outcomes; U.S. Institute of Medicine Board on Population Health and Public Health Practice. Gulf war and health. Vol. 7: Long-term consequences of traumatic brain injury. Washington (DC): National Academies Press; 2009.

5. Raymont V, Salazar AM, Lipsky R, Goldman D, Tasick G, Grafman J. Correlates of posttraumatic epilepsy 35 years following combat brain injury. Neurology. 2010;75(3): 224-29. [PMID:20644150] http://dx.doi.org/10.1212/WNL.0b013e3181e8e6d0

6. England MJ; U.S. Institute of Medicine Committee on the Public Health Dimension of the Epilepsies. Epilepsy across the spectrum: Promoting health and understanding. Washington (DC): National Academies Press; 2012.

7. ILAE Commission Report. The epidemiology of the epilepsies: Future directions. International League Against Epilepsy. Epilepsia. 1997;38(5):614-18. [PMID:9184609]

8. Perlin JB, Kolodner RM, Roswell RH. The Veterans Health Administration: Quality, value, accountability, and information as transforming strategies for patient-centered care. Am J Manag Care. 2004;10(11 Pt 2):828-36. [PMID:15609736]

9. Salinsky M, Spencer D, Boudreau E, Ferguson F. Psychogenic nonepileptic seizures in US veterans. Neurology. 2011;77(10):945-50. [PMID:21893668] http://dx.doi.org/10.1212/WNL.0b013e31822cfc46

10. Dworetzky BA, Strahonja-Packard A, Shanahan CW, Paz J, Schauble B, Bromfield EB. Characteristics of male veterans with psychogenic nonepileptic seizures. Epilepsia. 2005;46(9):1418-22. [PMID:16146437] http://dx.doi.org/10.1111/j.1528-1167.2005.13004.x

11. O’Neil ME, Carlson KF, Storzbach D, Brenner L, Freeman M, Quiñones A, Motu'apuaka M, Ensley M, Kansagara D. Complications of mild traumatic brain injury in veterans and military personnel: A systematic review. VA EvidenceBased Synthesis Program Reports. Washington (DC): Department of Veterans Affairs; 2013.

12. Congressional Budget Office. The Veterans Health Administration's treatment of PTSD and traumatic brain injury among recent combat veterans [Internet]. Washington (DC): Congress of the United States; 2012 Feb. Available from: http://www.cbo.gov/sites/default/files/cbofiles/attachments/ 02-09-PTSD.pdf

13. Public Health. VA health care utilization by recent veterans [Internet]. Washington (DC): Department of Veterans Affairs; 2013 [updated 2015 Jun 3]. Available from: http:// www.publichealth.va.gov/epidemiology/reports/oefoifond/ health-care-utilization/index.asp
14. Armed Forces Health Surveillance Center. Section 13: Neurology [Internet]. Silver Spring (MD): Armed Forces Health Surveillance Center; 2011 Oct. Available from: https://www.afhsc.mil/documents/pubs/documents/ CaseDefs/Web_13_NEUROLOGY_APR12.pdf

15. Holden EW, Grossman E, Nguyen HT, Gunter MJ, Grebosky B, Von Worley A, Nelson L, Robinson S, Thurman DJ. Developing a computer algorithm to identify epilepsy cases in managed care organizations. Dis Manag. 2005;8(1):1-14. [PMID:15722699] http://dx.doi.org/10.1089/dis.2005.8.1

16. Pugh MJ, Berlowitz DR, Kazis L. The impact of epilepsy on older veterans. Int Rev Neurobiol. 2007;81:221-33. [PMID:17433927] http://dx.doi.org/10.1016/S0074-7742(06)81014-7

17. Pugh MJ, Van Cott AC, Cramer JA, Knoefel JE, Amuan ME, Tabares J, Ramsay RE, Berlowitz DR; Treatment In Geriatric Epilepsy Research (TIGER) Team. Trends in antiepileptic drug prescribing for older patients with new-onset epilepsy: 2000-2004. Neurology. 2008;70(22 Pt 2):2171-78. [PMID:18505996] http://dx.doi.org/10.1212/01.wnl.0000313157.15089.e6

18. Ettinger AB, Copeland LA, Zeber JE, Van Cott AC, Pugh MJ. Are psychiatric disorders independent risk factors for new-onset epilepsy in older individuals? Epilepsy Behav. 2010;17(1):70-74. [PMID:19913462] http://dx.doi.org/10.1016/j.yebeh.2009.10.010

19. Copeland LA, Ettinger AB, Zeber JE, Gonzalez JM, Pugh MJ. Psychiatric and medical admissions observed among elderly patients with new-onset epilepsy. BMC Health Serv Res. 2011;11:84. [PMID:21504584] http://dx.doi.org/10.1186/1472-6963-11-84

20. Thurman DJ, Beghi E, Begley CE, Berg AT, Buchhalter JR, Ding D, Hesdorffer DC, Hauser WA, Kazis L, Kobau R, Kroner B, Labiner D, Liow K, Logroscino G, Medina MT, Newton CR, Parko K, Paschal A, Preux PM, Sander JW, Selassie A, Theodore W, Tomson T, Wiebe S; ILAE Commission on Epidemiology. Standards for epidemiologic studies and surveillance of epilepsy. Epilepsia. 2011; 52(Suppl 7):2-26. [PMID:21899536] http://dx.doi.org/10.1111/j.1528-1167.2011.03121.x

21. Hamid H, Fodeh SJ, Lizama AG, Czlapinski R, Pugh MJ, LaFrance WC Jr, Brandt CA. Validating a natural language processing tool to exclude psychogenic nonepileptic seizures in electronic medical record-based epilepsy research. Epilepsy Behav. 2013;29(3):578-80. [PMID:24135384] http://dx.doi.org/10.1016/j.yebeh.2013.09.025

22. World Health Organization. Chapter 3: Neurological disorders, a public health approach. In: Neurological disorders: Public health challenges. Geneva (Switzerland): World Health Organization; 2006.

23. Kobau R, Zahran H, Thurman DJ, Zack MM, Henry TR, Schachter SC, Price PH; Centers for Disease Control and 
Prevention (CDC). Epilepsy surveillance among adults19 states, Behavioral Risk Factor Surveillance System, 2005. MMWR. 2008;57(6):1-20. [PMID:18685554]

24. Holden EW, Thanh Nguyen H, Grossman E, Robinson S, Nelson LS, Gunter MJ, Von Worley A, Thurman DJ. Estimating prevalence, incidence, and disease-related mortality for patients with epilepsy in managed care organizations. Epilepsia. 2005;46(2):311-19. [PMID:15679513] http://dx.doi.org/10.1111/j.0013-9580.2005.30604.x

25. Epidemiology Program, Post-Deployment Health Group, Office of Public Health. Analysis of VA health care utilization among Operation Enduring Freedom (OEF), Operation Iraqi Freedom (OIF), and Operation New Dawn (OND) Veterans: Cumulative from 1st Qtr FY 2002 through 4th Qtr 2014 (October 1, 2001-September 30, 2014) [Internet]. Washington (DC): Veterans Health Administration, Department of Veterans Affairs; 2015. Available from: http:// www.publichealth.va.gov/docs/epidemiology/healthcareutilization-report-fy2014-qtr4.pdf

26. Pugh MJ, Orman JA, Jaramillo CA, Salinsky MC, Eapen BC, Towne AR, Amuan ME, Roman G, McNamee SD, Kent TA, McMillan KK, Hamid H, Grafman JH. The prevalence of epilepsy and association with traumatic brain injury in veterans of the Afghanistan and Iraq wars. J Head Trauma Rehabil. 2015;30(1):29-37. [PMID:24695268] http://dx.doi.org/10.1097/HTR.0000000000000045

27. Annegers JF, Hauser WA, Coan SP, Rocca WA. A population-based study of seizures after traumatic brain injuries. N Engl J Med. 1998;338(1):20-24. [PMID:9414327] http://dx.doi.org/10.1056/NEJM199801013380104

28. Brenner LA, Betthauser LM, Homaifar BY, Villarreal E, Harwood JE, Staves PJ, Huggins JA. Posttraumatic stress disorder, traumatic brain injury, and suicide attempt history among veterans receiving mental health services. Suicide Life Threat Behav. 2011;41(4):416-23. [PMID:21599727] http://dx.doi.org/10.1111/j.1943-278X.2011.00041.x
29. Jakupcak M, Cook J, Imel Z, Fontana A, Rosenheck R, McFall M. Posttraumatic stress disorder as a risk factor for suicidal ideation in Iraq and Afghanistan War veterans. J Trauma Stress. 2009;22(4):303-6. [PMID:19626682] http://dx.doi.org/10.1002/jts.20423

30. LaFrance WC Jr, Miller IW, Ryan CE, Blum AS, Solomon DA, Kelley JE, Keitner GI. Cognitive behavioral therapy for psychogenic nonepileptic seizures. Epilepsy Behav. 2009;14(4):591-96. [PMID:19233313] http://dx.doi.org/10.1016/j.yebeh.2009.02.016

31. Hopp JL, LaFrance WC Jr. Cognitive behavioral therapy for psychogenic neurological disorders. Neurologist. 2012; 18(6):364-72. [PMID:23114668] http://dx.doi.org/10.1097/NRL.0b013e31826e8ff5

Submitted for publication October 17, 2014. Accepted in revised form May 21, 2015.

This article and any supplementary material should be cited as follows:

Rehman R, Kelly PR, Husain AM, Tran TT. Characteristics of Veterans diagnosed with seizures within Veterans Health Administration. J Rehabil Res Dev. 2015;52(7): 751-62.

http://dx.doi.org/10.1682/JRRD.2014.10.0241

ResearcherID: Rizwana Rehman, PhD: K-5524-2015; Pamela R. Kelly, DHA, MBA/HCM: K-5538-2015

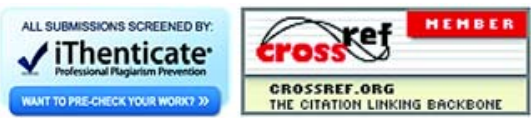

